\title{
Lazer e Produtividade no Trabalho ${ }^{1}$
}

\section{Maria de Fátima Aguiar ${ }^{2}$}

RESUMO: Aborda o lazer como tecnologia de qualidade de vida no trabalho. Identifica em Fortaleza empresas que estão investindo no lazer para seus funcionários, com o objetivo de melhorar a qualidade de vida no trabalho e da produtividade, já registrando resultados significativos.

PALAVRAS-CHAVE: lazer na empresa, produtividade, qualidade de vida no trabalho.

ABSTRACT: This paper presents the leasure time as a technology of life quality at work. Many companies in Fortaleza (Brazil) are investing in leasure time for their employees in order to impreve life quality at work and their performance. It has been reported relevant results with this practice.

KEYWORDS: business leisure, productivity, quality of life at work.

\section{Introduçāo}

A certeza de que as inovações tecnológicas, por si só, promoveriam o bemestar da humanidade, não mais se sustenta. Esta reflexão está sugerindo novo modelo de organização da sociedade, voltado para as necessidades do ser humano, que vão além das condições de sobrevivência, como segurança, socialização e auto-realiza-

1. Dissertaçāo apresentada no curso de mestrado em Administraçāo de Empresas da Universidade de Fortaleza (UNIFOR).

2. Bacharel em Turismo, com especializaçāo em Educaçāo. Mestre em Administraçāode Empresas. Professora do curso de Turismo da UNIFOR.

End.: Rua Joaquim Lima, 1320, apto. 204 - 60155-000 - Fortaleza - CE - Brasil.

E-mail: mariafatima.aguiar@bol.com.br 
ção; novos estudos para a reurbanização das cidades ereestruturação organizacional das empresas, ensejam a compreensão de que estes aspectos exercem grando influência na qualidade de vida das populações urbanas, mormente no que tange à disponibilidade e entusiasmo diante do desempenho.

A análise da organização do trabalho, na sociedade atual,permite a visualização da grande contribuição do sistema tradicional de produção para o aumento da melhoria da produtividade e das limitações impostas ao trabalhador, pelas próprias condições de vida e trabalho na sociedade industrial.

Os fatores intervenientes no aumento da produtividade estão presentes no estudo da organização do trabalho desde o início do século, mas só a partir da década de 70, os indicadores referentes às necessidades e aspirações humanas ganham maior relevância diante do desafio da produtividade das organizações, em busca de competitividade, incluindo-se, agora na avaliação da produtividade, a responsabilidade social da empresa. Este fato sugere uma mudança na administração superior das organizações, orientada pela compreensão da qualidade de vida no trabalho, como um aspecto tão importante quanto a modernização tecnológica.

Neste contexto, o lazer vem despertando a atenção de estudiosos da reestruturação organizacional e de organizações, que começam a percebê-lo como importante indicador de qualidade de vida, pelas suas funções compensatória e utilitarista, que ajudam no desenvolvimento das faculdades cognitivas, intuição, criatividade, sociabilidade e da capacidade de simbolizare interagir, importantes nas novas formas de organização do trabalho.

A sociologia do lazer sugere o exame da sociedade onde o lazer acontece, como meio de melhor compreender a sua dinâmica. Portanto, a falta de políticas de lazer no planejamento urbano e na gestão das cidades brasileiras, implicando a ausência de opções de lazer democráticas e saudáveis para o trabalhador e sua família, justifica as ações de lazer patronal, quer pela responsabilidade social, quer pela potencialidade do lazer no desenvolvimento informal de recursos humanos.

Hoje, no mundo todo, 20 mil organizações oferecem programas de lazer para seus funcionários, com vistas à melhoria da produtividade (Durães, 1998). No Brasil apesar deste número ainda não ser conhecido, sabe-se que a atividade vem sendo desenvolvida, em grandes empresas, desde a década de 70, principalmente nas regiões mais industrializadas, com significativo impulso nos últimos anos, quando programas de lazer começaram a ser desenvolvidos nas próprias organizações. O Serviço Social da Indústria (SESI) vem envidando esforços nesse sentido, em 26 estados brasileiros e no Distrito Federal, mas a atividade ainda parece incipiente.

No Ceará, qual é a situação ? As empresas cearenses estão atentas a esta necessidade dos trabalhadores e a possibilidade de melhorar o desempenho destes, através dos benefícios do lazer?

A dissertação Lazer e Produtividade no Trabalho examina como o assunto vem sendo tratado pelos estudiosos do lazer e da ciência administrativa, na perspectiva de desencadear o processo de discussão sobre a importância do lazer na produtividade do trabalhador, no meio acadêmico e empresarial cearense.

O trabalho baseia-se, principalmente, nas idéias de Joffre Dumazedier e
Nelson Carvalho Marcellino sobre lazer como necessidade básica do homem, como bem útil, capaz de restaurar energias, promover integração e sociabilidade do trabalhador e desenvolver sua criatividade e faculdades cognitivas; utiliza ainda as obras de Cristina Gattai, Peter Drucker e Edward Deming. Cristina Gattai, na percepção dos benefícios do lazer para a melhoria da produtividade, quandoinserido no cotidiano das empresas; Peter Drucker e Edward Deming na compreensão da qualidade como condição básica para a produtividade, e da produtividade como condição básica para a competitividade das organizações, entendendo-se produtividade como desempenho econômico e social da empresa .

A pesquisa tem por objetivo conhecer o posicionamento das empresas cearenses em relação ao lazer do trabalhador, avaliar a maneira como os programas de lazer, desenvolvidos pelas empresas, estão sendo concebidos e conhecer a relação que está sendo estabelecida por estas empresas entre lazer e desempenho. Foi escolhida uma amostra de doze empresas da regiãometropolitana de Fortaleza, que desenvolvem programas de lazer há pelo menos seis meses, dentre as cinqüenta que trabalham em parceria com o SESI. Os dados foram colhidos através de questionário aplicado junto aos gerentes de recursos humanos.

\section{Ampla Compreensāo do Lazer}

O lazer tem se constituído assunto polêmico, até mesmo para seus estudiosos, pela complexidade de suas implicações filosóficas, sociológicas e psicológicas. Sua origem é controvertida, para historiadores e sociólogos. Na visão de Dumazedier (1979), nas sociedades pré-industriais, o trabalho obedecia o rítmo natural da vida; as festas estavam ligadas ao culto e à tradição. Não existia o lazer em si. O lazer contemporâneo é característico da civilização industrial, dado que este pressupõe trabalho, enquanto o lazer das sociedades pré-industriais, restrito a filósofos e fidalgos, caracterizava-se pelo ócio. A separação nítida entre tempo, espaço de trabalho e lazer deu-se com a industrialização. Munnè (1980) aborda duas concepções filosóficas que ainda hoje influenciam os estudos do lazer: a burguesa, que enaltece e cultiva a moral do trabalho, e a marxista, que se preocupa com a conquista e o uso do tempo livre, entendendo que a riqueza da sociedade depende da produtividade, e que riqueza e lazer sãocondiçõespara o pleno desenvolvimento das faculdades intelectuais.

Registram-se, também, duas tendências na conceituação do lazer: uma com enfoque para o aspecto atitude, que vê o lazer como um estilo de vida, em que tempo livre determinado não é a condição básica; outra, que exige um tempo livre do trabalho e de outras obrigações. Os autores brasileiros não apresentam tendências claramente definidas em torno dessas duas linhas, mas seguem a tendência atual, que une tempo e atitude (Marcellino, 1990).

Uma definição amplamente difundida é a de Dumazedier (1973) para quem lazer é 
... conjunto de ocupaçōes às quais o individuo pode entregar-se de livre vontade, seja para repousar, seja para divertir-se, recrear-se e entreter-se ou ainda para desenvolver sua formaçāo desinteressada, sua participação social voluntária, ou sua livre capacidade criadora, após livrar-se ou desembaraçar-se das obrigaçōes profissionais, familiares e sociais.

As funções precípuas do lazer são: descanso, divertimento e desenvolvimento pessoal. A função de descanso está ligada ao aspecto compensatório do desgaste das energias, liberando a fadiga física e mental; a função de divertimento é importante no processo de ruptura da monotonia cotidiana, interferindo na personalidade do indivíduo, ajudando-o a suportar as regras e as pressões da sociedade. A função de desenvolvimento da personalidade traz a possibilidade de engrandecimento do ser, pelo crescimento pessoal e social.

A psicossociologia traz sua contribuição ao tema, analisando a complexidade e a ambigüidade como características próprias do lazer, e como estas interferem no plano individual e social. Munné (1980) resume as funções do lazer em psicoterapêuticas e socioterapêuticas.

A abordagem utilitarista do lazer, entendida como função compensatória (recuperação da força de trabalho) ou sua utilização como instrumento de desenvolvimento, tem gerado muitas polêmicas, quando adiscussãonão obedece ao princípio dialético. (Marcellino, 1990). Se muitos autores a vêem como instrumento de alienação, em prol de determinadas ideologias, outros apontam sua possibilidade de contribuição até mesmo para a tranqüilidade, a ordem e a segurança social.

É complicada a separação estanque entre função compensatória e utilitarista do lazer. Cada uma tem sua própria importância para o desenvolvimento da pessoa e da sociedade. A prática do lazer nas empresas vem sendo estimulada pelos resultados positivos na melhoria da qualidade de vida dos funcionários e no retorno econômico para a empresa, na medida em que abranda os problemas de relacionamento, melhora a auto-estima dos trabalhadores, podendo resultar em ganhos para empregados e empregadores (Medeiros, 1971).

Essa potencialidade do lazer explica a importância que o assunto vem assumindo no processo de humanização do trabalho na sociedade contemporânea, com o setor de serviços avançando sobre o setor industrial e apontando para o surgimento de uma pretensa sociedade do lazer, onde funcionarão, de forma mais harmoniosa, o setor tradicional e o informal, com o tradicional limitando o cresci mento forçado da produção, para dispensar mais atenção ao planejamento urbanís tico, aos serviços de educação, saúde, formação profissional, multiplicidade dos empregos nos setores sociais, culturais e pedagógicos do lazer e no setor formal ou familiar, com formas antigas ou novas de organização comunitária que estimulem e revalorizem o trabalho individual e a iniciativa pessoal, a vida comunitária, a relações afetivas e a realização do ser, em todas as suas dimensões (Krippendorf 1989).

\section{Produtividade}

Otermo constitui-se palavra-chave no meio empresarial, por sua importância no asseguramento da sobrevivência e para o sucesso das empresas, no atual contexto econômico. Mas a noção lógica da produtividade como medida do progresso técnico e econômico remonta ao século XIX, apesar das primeiras definições, no sentido econômico e social que hoje lhes é atribuído, terem surgido apenas na metade do século XX (Drucker, 1992).

Os conceitos de produtividade inspiradores deste estudo são o de Drucker (1992), sintetizado em rendimento dos recursos, e o de Deming (1990), sintetizado na idéia da produtividade como uma espécie de estado da organização, em que o aproveitamento dos recursos leva àeficácia, implantando uma mentalidade gerencial propícia a o aproveitamento das oportunidades, fomentando ações fortalecedoras da saúde financeira da empresa, do seu desempenho social e aumentando sua competitividade.

A produtividade depende do desenvolvimento dos recursos humanos, envol vendo habilidade, vontade, interesse, consciência, técnica, gerenciamento, em contexto social, econômico e político.

Qualidade e produtividade, juntamente com tecnologia e recursos humanos, formam os principais indicadores do desempenho produtivo. O mix destes componentes vem apresentando variações, de acordo com o contexto das organizações, com notório avanço do componente tecnológico, a partir da Segunda Guerra mundial. Só mais tarde a qualidade ganha maior importância, com a certeza de seu papel na melhoria da produtividade. Deming(1990) vê naqualidade o caminhopara a revolução da administração, rumo à competitividade, que só se viabiliza através de mudanças nas relações entre empresas e governos e entre patrões e trabalhadores, baseada no compromisso da continuidade da empresa no mercado. Isto requer dos trabalhadores confiança e entusiasmo, condições proporcionadas pelos empregadores através da proteção do investimento, assegurando dividendos e empregos e melhorand o a qualidade de vida no trabalho. Esta filosofia abandona a avaliação do desempenho da empresa com base apenas nos dividendos distribuídos, passando a considerar também sua responsabilidade social.

A promoção da qualidade, proposta por Deming (1990), responsabiliza o sistema pelo desempenho, devendo o treinamento voltar-se para a compreensão do funcionamento sistêmico de todos os processos, o medo combatido e a criatividade incentivada. A qualidade melhorada aumenta a produtividade, mas para se ter certeza é preciso monitorá-la adequadamente, pois a mensuração da qualidade e da produtividade pode não apresentar contribuição ao processo de melhoria de desempenho, se estiver limitada aos resultados quantitativos. A medição do desempenho deve ser utilizada não apenas com a intenção de controle, mas também de previsão, estimativa, tomada de decisão, solução de problemas e motivação.

Tanto no estudo da qualidade como no da produtividade, registra-se certa dificuldade na construção de indicadores de avaliação de desempenho, por causa da 
complexidade dos seus aspectos subjetivos. Para Tirone (1993), os principais tipos de indicadores relacionam-se à satisfação dos clientes, participação no mercado desenvolvimento de novos mercados; desempenho de produtos e serviços; desempenho operacional e financeiro; de fornecedores; de recursos humanos, na responsabilidade pública e no espírito comunitário.

Recursos humanos constituem-se no desafio das organizações, pois a velocidade das mudanças no mundo do trabalho sugere constante exame das novas competências requeridas. O termo competência é, muitas vezes, empregado apenas com sentido de qualificação. A noção de qualificação está associada às ciências sociais, e a de competência aos conceitos de capacidades e habilidades herdados das ciências humanas. É necessária a ampliação do conceito de competência, com base nos princípios construtivista e sociointeracionista, a partir da contribuição de diversas áreas, obedecendo ao princípio da interdisciplinaridade (Manfredi, 1998).

A formação de novas competências deve atender às novas demandas do mercado (Schermerhorn Jr., 1999) e está acontecendo com maior sucesso nas empresas que vêm adotando uma nova postura, tornando-se organizações de aprendizagem e promovendo a poliqualificação do trabalhador, desenvolvendo, além das competências técnicas requeridas, outras habilidades que lhe favoreçam uma postura crítica em relação aos processos produtivos; o novo foco aponta para as dimensões do ser, fazer e agir, que proporcionam as demais condições de interação, de forma mais democrática, no mundo do trabalho (Mariotti, 1995).

A avaliação das competências, nas organizações modernas, deve processarse observando aspectos como o compromisso das pessoas em torno de um propósito superior da organização, o desenvolvimento de lideranças responsáveis, a formação de equipes multidisciplinares, o estabelecimento de parcerias orgânicas, a promoção de redes de conhecimento e fluxo correto de informações (Somerville e Mroz apud Drucker, 1997)

Não existe uma teoria organizacional ideal que responda às incertezas das aceleradas mudanças nas estruturas empresariais. Contudo, há forte indício de que as organizações serão moldadas de forma cada vez mais diferentes, por propósitos, tipos de atividade, pessoas e culturas. Para Drucker (1997) até o próprio significado das organizações está mudando, à medida que a compreensão da institucionalização da sociedade e da real função da administração, cujo papel consiste na melhoria do desempenho econômico das empresas, na realização de um trabalho mais produtivo, torne o trabalhador mais realizado e empreendedor na responsabilidade para com os impactos sociais. Deming (1990) afirma ser o papel da administração indissociável do bem-estar da empresa, que caracteriza-se, principalmente, pelo seu sistema humano.

Já existem muitas organizações onde o velho paradigma "corações e máquinas" está sendo substituído lentamente, pelo paradigma "corações e mentes" A viabilidade dessas mudanças depende não somente da implantação de novos padrões tecnológicos, mas principalmente da implantação de novas políticas de gestão, o que requer a modernização das relações de trabalho. Segundo Morin (1999), há um processo de mundialização patente e violento, baseado na técnica e na economia, mas há um segundoprocesso, ainda latente, baseado no humanismo, na democracia na compreensão entre os povos e na cidadania, voltado para a lógica do ser, segundo a qual viver é expandir-se de forma afetiva e intelectual, questionando a lógica da mera inteligência artificial e das máquinas.

As organizações tendem a compreender a complexidade da natureza do ser e como isso interfere no sistema produtivo, e a considerar, inclusive, aspectos específicos da cultura dos grupos, valorizando o processo de resgate de dimensões esquecidas na cultura das pessoas. Tal resgate contribuirá para a integração da inteligência artificial e emocional, melhorando os processos de aprendizagem, o ambiente organizacional e o desempenho (Mariotti, 1995)

Agindo assim, as empresas estão também resgatando o gosto do ser humano pelo trabalho, pela possibilidade real de desenvolvimento e realização pessoal, e não apenas como forma irrecusável de sobrevivência.

Tem-se, portanto, duas formas de conceituar resultados: a primeira, através do raciocínio linear e a segunda através do raciocínio sistêmico. No raciocínio linear, os dados financeiros são suficientes para explicar os resultados organizacionais; pelo raciocínio sistêmico, além dos dados mensuráveis, são levados em consideração a motivação, a sinergia e o desempenho social da empresa. No desempenho social da empresa, a variável qualidade de vida no trabalho vem assumindo expressão significativa, porque não se pode falar de qualidade total, sem incluir programas de melhoria da qualidade de vida no trabalho. Para França (1996), qualidade de vida no trabalho (QVT) consiste nas ações de uma empresa para a implantação de melhorias e inovações gerenciais, tecnológicas e estruturais no ambiente de trabalho. Os conceitos de QVT apresentam-se com vários enfoques, como grau de satisfaçãoda pessoa com a empresa, condições ambientais e promoção da saúde, dentre outros.

Se um dos maiores desafios das empresas é criar condições para que os esforços de seu pessoal se mobilizem na realização dos seus objetivos, a tecnologia de QVT deve ser utilizada nesse sentido; porémé necessário sensibilidade para com as reais necessidades do trabalhador. Fernandes (1996) afirma que a QVT se torna indispensável à produtividade e à competitividade das empresas, nãopodendo mais ser ignorada ou tratada de forma paliativa no gerenciamento dos recursos humanos, constituindo-se excelente reflexo do ambiente global da empresa. Dentre os principais indicadores de QVT, levantados por França, encontra-se o lazer.

\section{Trabalho e Lazer}

A partir da compreensão dos benefícios do lazer, organismos internacionais como a Organização das Nações Unidas (ONU) passaram a se ocupar do assunto, hoje presente nas constituições da maioria dos países democráticos, inclusive na atual Constituição Brasileira. 
Contudo, nem todos têm acesso ao lazer e isto se reflete na sociedade, de diferentes formas, contribuindo para o estresse característico das estruturas urbanas que negligenciam essa necessidade básica de sua população.

Se o lazer promove o equilíbrio da personalidade, libera e renova energias, proporciona segurança emocional, contribui para com os processos de aprendizagem, de revelação e formação de lideranças, de desenvolvimento do indivíduo, o conceito que liga o trabalho à esfera da produção e o lazer à esfera improdutiva, não deve mais ecoar nas modernas organizações.

Todavia, esta compreensão não se constituiu o legado da visão racional. Se por um lado a racionalidade proporcionou o avanço das ciências que contribuíram para o desenvolvimento tecnológico, por outro separou o lazer da esfera do cotidiano e do trabalho, e o processo de urbanização priorizou os espaços industriais, em detrimento dos espaços habitacionais e de lazer, desencadeando problemas que afetam, principalmente, a classe operária, cujas condições de moradia e de trabalho são inadequadas e estressantes.

Por muito tempo a administração preocupou-se apenas com o aumento da produção, para a melhoria do desempenho das empresas. A contribuição de várias teorias vem, aos poucos, proporcionando melhor compreensão da importância do atendimento das necessidades e aspirações dos trabalhadores, para a efetiva melhoria da produtividade nas organizações (Gattai, 1993).

A civilização industrial instalou o conceito utilitarista do tempo, traduzida na idéia de que tempo é dinheiro e ensejou o surgimento do lazer, tal como é hoje concebido: as constantes reivindicações dos trabalhadores por melhores condições de trabalho, ao longo da história do capitalismo, incluíram sempre a redução da jornada de trabalho, aumentando consideravelmente o tempo livre, que vem contribuindo para o tempo de lazer. Contudo, a maioria dos trabalhadores restringe o prazer ao lazer, ao ponto de poucos sentirem-se satisfeitos com seu trabalho.

Por suas amplas possibilidades, o lazer vem se constituindo tema importante nas empresas que entenderam que a formação das novas competências deve processar-se sob a orientação do raciocínio sistêmico, para que a promoção da sinergia necessária ao aumento da produtividade possa acontecer. Loureiro (1998) afirma que em quase todas as atividades de lazer e desfrute do tempo livre encontrase, pelo menos, uma forma de aprender.

O interesse da sociologia do trabalho pelo lazer, até os anos 60 , esteve na preocupação de melhorar as condições de trabalho e compensar suas imperfeições. Nos anos 70, surge a oposição entre segmentalistas, que apresentam as atividades de lazer como alternativa de futuro, em relação ao trabalho, e os holistas, que propõem uma revisão do trabalho, de forma que se possa obter maior progresso técnico e socia das tarefas, com trabalho mais prazeroso (Parker, 1978). Na metade da década de 60 começaram a surgir as primeiras mudanças nas situações de trabalho, em relação ao lazer.

A discussão é complexa. Dumazedier (1980) sugere que o fenômeno decorrente das relações entre trabalho e lazer seja examinado, considerando a dualidade do lazer como produto da situação de trabalho e como ação direta ou indireta sobre o trabalho, os aspectos filosóficos da relação entre ser e ter e a possibilidade de separar mais ainda o trabalho do lazer, ou aproximar mais estas esferas da vida.

As atuais condições de vida dos trabalhadores, de um modo geral, não lhes permite o desfrute do lazer. A ação das instituições para amenizar os problemas decorrentes dessa condição torna-se urgente.

\section{Lazer Empresaria}

Compreendendo os benefícios do lazer e atentas à realidade descrita, lgumas organizações começaram a incluir o assunto em sua pauta de planejamento, resultando em maior atenção para os lazeres de fim de semana e férias, como clubes, colônias de férias, lazeres da hora do almoço, como salas de TV, cinema e salão de jogos, pausas rápidas para cafezinho e, mais recentemente, vêm introduzindo maiores flexibilidades na administração do tempo diário de trabalho, com pausas para repouso e descontração. Os resultados dessas ações de lazer, segundo Gattai (1993) (1993), refletem-se na melho, consequentemente, em maior rendimento.

A compreensão do novo papel social das empresas, com base na competência e na qualidade, requer a adoção de técnicas para o desenvolvimento de todas as potencialidades do trabalhador. Muitas empresas estão percebendo a adequação do o desenvolvimento da comunicação, da sociabilidade, da vivência em grupo, entre tantos outros benefícios dolazer empresarial, que pode ser considerado uma estratégia para o desenvolvimento informal de recursos humanos (Daminelle apud Marcellino, 1995).

O SESC foi pioneiro no Brasil, tanto nos estudos quanto na oferta de programas de lazer para os trabalhadores do setor de serviços e seus familiares. Estimula o lazer como parte de um conjunto de medidas para a melhoria da qualidade de vida.

Os trabalhadores da indústria passaram a ter esses programas através do SESI, que possui, hoje, a maior estrutura de lazer empresarial do país e constitui-se referência em lazer para a América Latina. Pioneiro em atividades de lazer no ambiente de trabalho, há mais de dez anos, incentiva programas de lazer nas indústrias. Os programas consistem em diversas atividades esportivas e socioculturais.

O SESI estimula as empresas a oferecer programas de lazer no próprio ambiente de trabalho, em razão da potencialidade dessas atividades na geração de benefícios como prevenção da saúde ocupacional e do estresse, melhoria do rendimento funcional, redução do número de acidentes de trabalho, diminuição dos

3. DAMINELLI, Mário Reflexōes sobre cultura e lazer na empresa. In: MARCELLINO, Nelson Carvalho. Lazer formação e atuação profisssional. Campinas: Papirus, 1995. 
gastos com despesas médicas, melhoria das relações humanas e de trabalho e aumento da produtividade, desenvol vendo, ainda, a criatividade e contribuindo para a criação de um ambiente laboral harmonioso e participativo (SESI, s.d.)

Um dos programas que vem tendo significativa aceitação é o "Ginástica na Empresa", desenvolvido no Brasil, pioneiramente, pelo SESI, em 1997, e já implantado em 20 regionais do sistema, como aliado na prevenção de doenças ocupacionais. O programa conta com a adesão de aproximadamente 500 empresas e 190 mil trabalhadores (Ramalho, 1999).

As atividades desenvolvidas pelas empresas são as mais diversas; das mais simples, como jogos de mesa, na hora do almoço, às atividades de corais, teatros, campeonatos esportivos, festivais de conto e poesia, aulas de alongamento e dança, dentre outros.

Avaliações sistematizadas dos resultados das ações de lazer ainda não são comuns, excetuando-se o programa "Ginástica na Empresa". Algumas empresas têm feito avaliações qualitativas que apresentam bons resultados. O Banespa utiliza questionários, reuniões e observaçãoparticipante. O gerente de recursos humanos da Tinkem do Brasil afirma que as atividades de lazer atuampositivamente na melhoria da produtividade do trabalhador, que, tendo mais acesso ao lazer, adquire melhor preparo físico e equilíbrio das funções do corpo, ficando predisposto a melhor desempenho profissional, evitando doenças prematuras, problemas de postura e doenças profissionais, e que esta postura da cmpresa também a beneficia, no que se refere ao aumento do compromisso do funcionário com a organização (Boccato, apud Gattai, 1993).

Gattai afirma que existe consenso sobre a contribuição do lazer para humanizar o cotidiano dos trabalhadores e que

o espaço de lazer, quando inserido no cotidiano da empresa, passa a ter significativa importância para os trabalhadores que têm a oportunidade de se expressar livremente e de demonstrar toda sua potencialidade humana. Por outro lado, a empresa "ganha" a nivel de aumento de produtividade, pois seus funcionários estarão mais integrados ao ambiente de trabalho (Gattai, 1993).

Acredita-se que a compreensão das dimensões do lazer e as experiências de empresas, que vêm investindo no lazer como tecnologia de qualidade de vida, possam motivar outras organizações que buscam competitividade a se utilizarem dessa estratégia, contribuindopara a melhoria das funções básicas da administração.

\section{Situaçāo no Ceará}

Como acontece em outras regiões do país, tanto o SESI quanto o SESC vêm promovendo atividades de lazer para os trabalhadores cearenses, disponibilizando estruturas de recreação como centros de lazer, desenvolvendo atividades culturais como cursos, oficinas, festivais, apresentações musicais, dança, teatro, coral, bandas, artes plásticas e atividades esportivas diversas, incluindo os campeonatos.

Existem também várias iniciativas isoladas de organizações que promovem lazer para seus funcionários e familiares, ou associados, através de espaços próprios ou conveniados, como os clubes.

No que se refere à tentativa de inserir atividades de lazer no cotidiano das empresas, destaca-se o trabalho que o SESI desenvolve através de algumas experiências recentes. Trata-se dos programas "Ginástica na Empresa" e "Sobremesa com Arte", consistindo o último na apresentação de programas culturais nas empresas, na hora do almoço, e a disponibilidade de livros para serem emprestados aos trabalhadores. Estes programas foram implantados há mais de um ano e em setembro de 1999, foi lançado, de forma experimental, um programa inédito no Brasil, intitulado Música Erudita no Canteiro de Obras, que vem sendo desenvolvido com algumas empresas da construção civil.

O SESI vem trabalhando com cerca de 50 empresas na divulgação, implantação e acompanhamento desses programas, bem como na assistência para realização de outros eventos na área de lazer cultural ou esportivo.

O estudo em pauta incluiu a realização de uma pesquisa em empresas do ramo industrial, localizadas na região metropolitana de Fortaleza, que oferecem programas de lazer para seus funcionários. A amostra foi composta por 12 empresas, que vem desenvolvendo programas de lazer nas próprias instalações, há pelo menos três meses, em parceria com o SESI-Ceará.

As variáveis consideradas foram lazer e produtividade do trabalhador e os indicadores foram de saúde e bem-estar, de clima organizacional e desempenho produtivo. No âmbito da saúde (estresse e lesões por esforço repetitivo-LER); clima organizacional (relacionamento entre trabalhadores, entre trabalhadores e dirigentes, disposição para o trabalho, concentração nas tarefas, motivação para participar de novas tarefas, motivação para participar de treinamentos e cursos e ambiente de trabalho). Indicadores de recursos humanos (absenteísmo, rotatividade da mão-deobra e acidentes de trabalho com afastamento). Os indicadores de desempenho produtivo foram selecionados entre indicadores de qualidade e produtividade na indústria brasileira, que vêm sendo utilizados pela Confederação Nacional da Indústria (CNI), desde 1994 (BNDES, CNI,SEBRAE, 1998).

Os dados secundários foram obtidos através de contatos com técnicos do SESI-Ceará, e os primários através da aplicação de um questionário junto aos gerentes de recursos humanos das empresas selecionadas.

As empresas que constituíram a amostra pertencem aos setores de alimentação, construção naval, embalagens, metalúrgico, têxtil e confecção, caracterizando-se seis como médias empresas e as outras seis como grandes.

Todas estimulam o lazer de seus funcionários, incentivando a utilização das estruturas de lazer do SESI e oferecendo outras opções. Em parceria com o SESI, quatro empresas promovem o programa "Ginástica na Empresa", onze promovem o programa "Sobremesa com Arte"' e cinco oferecem o programa "Caixa Estante". 
Foram também mencionadas diversas iniciativas independentes, em espaços próprios, como grêmios, ginásio esportivo, quadras, quiosque, sala de lazer, casa de praia, programas esportivos (ênfase para futebol masculino) e culturais (biblioteca própria, coral, teatro, semana da arte), city-tour, jogos de mesa, ginástica estética, sala de repouso, eventos comemorativos, excursões e fins de semana na praia.

A totalidade das empresas foi motivada a promover ações de lazer, na perspectiva de melhorar a qualidade de vida no trabalho e, mais da metade, na perspectiva de melhorar a produtividade.

Os programas de lazer foram implantados paralelamente a outros programas para a melhoria da qualidade de vida no trabalho, na maioria das empresas. A participação dos trabalhadores nessas atividades é espontânea, sendo a ginástica laboral obrigatória em duas delas. Os funcionários são envolvidos nas ações de lazer através de sondagens que subsidiam o planejamento, opinando e ajudando na organização; os monitores da ginástica laboral são voluntários.

A participação dos trabalhadores dá-se de forma indistinta com relação ao sexo, ao nível cultural e à natureza do trabalho. As empresas assumem totalmente 0 custo de todos os programas, exceto os do "Sobremesa com Arte", bancado pelo SESI. Quanto à avaliação, apenas uma empresa faz controle estatístico do programa "'Ginástica na Empresa", mas todas afirmam avaliar de forma empírica, registrando benefícios gerais promovidos pelo lazer no desempenho dos funcionários, como demonstra o abaixo explicitado:

- Na saúde e bem-estar

- redução do estresse: 10

- redução dos índices de LER: 02

- No clima organizacional da empresa

- melhoria do relacionamento entre trabalhadores e entre trabalhadores e dirigentes: 11

- melhoria da disposição para o trabalho: 10

- melhoria da concentração nas tarefas: 02

- melhoria da motivação para participar de novas tarefas, treinamentos e cursos: 07

- melhoria geral do ambiente de trabalho: 10

- No desempenho produtivo dos funcionários

- apenas duas empresas registraram redução de índices de absenteísmo, de rotatividade de mão-de-obra e de acidentes de trabalho. Nenhuma empresa respondeu às perguntas sobre os benefícios no desempenho produtivo de qualidade, pelo fato de não fazerem controle estatístico.

Percebe-se que a avaliação sistemática das ações de lazer não se constitui ainda uma prática nessas empresas, em que a crença de que os resultados são positivos para o funcionário e para a empresa é generalizada. No entanto, a ausência da avaliação através de controle estatístico não compromete os resultados apresentados, como se vê em Deming (1990) e Drucker (1997).

Mesmo não estando ainda consolidado o processo de inserção das atividades de lazer no cotidiano dessas empresas, conforme Gattai (1993), já são bastante sensíveis os benefícios do lazer, principalmente na melhoria doclima organizacional a partir do desenvolvimento destas atividades.

A maioria das empresas implantou os programas na perspectiva da melhoria da qualidade de vida no trabalho e na melhoria da produtividade do trabalhador. Esta posição poderia sofrer crítica, a partir de uma visão unilateral, que poderia classificála como ação a serviço da ideologia capitalista; no entanto, numa visão democrática, considera-se positiva, a partir da compreensão do lazer como necessidade do indivíduo e como um bem últil.

\section{Consideraçōes Finais}

As empresas cearenses, ou aquelas que operam no Ceará, especificamente na região metropolitana de Fortaleza, estão começando a se preocupar com o lazer de seus funcionários, passando a incluir $\mathrm{em}$ seus programas, para melhoria de qualidade de vida no trabalho, algumas ações de lazer.

As ações desenvolvem-se de forma isolada e em parceria com o SESI; a maioria dos programas são concebidos com base nas reivindicações dos funcionários e através de sondagens; os funcionários são envolvidos nos programas de lazer, em nível de plancjamento c organização; a coordenação dessas ações é de responsabilidade do Departamento de Recursos Humanos. Registram-se esforços para viabilizar o lazer dentro e fora da empresa, mas as atividades de lazer ainda não estão devidamente inseridas no cotidiano das empresas. As cmpresas vêm observando melhorias no desempen ho dos funcionários, relacionadas à praticado lazer, na saúd e bem-estar da equipe e no clima organizacional.

A pesquisa infere que, em Fortaleza, a exemplo do que vem ocorrendo em muitas cidades do Brasil, muitas empresas estão começando a perceber a possibilidade da oferta de lazer para seus funcionários como uma tecnologia de qualidade de vida, de grande potencialidade para a melhoria da produtividade.

\section{Referências Bibliográficas}

AGUIAR, Maria de Fátima. Lazer e produtividade no trabalho. Tese (Mestrado em Administração de Empresas,

Universidade de Förtaleza, Ceará.
NDES, CNI, SEBRAE. 1998. Indicador

BNDES; Brasília: CNI: DF: SEBRAE. qualidade e produtividade na induistria brasileira, 1997. Rio de Janeiro:

DEMING, W. Edwards. 1990. Oualidade: a revc

çăo da administração. Traduçāo: Clave Comunicação e Recursos 997. A organizą̧ão do futuro. Co 
DRUCKER, Peter Ferdinand. 1992. Administrando para o futuro: os anos 90 e a virada do século. São Paulo: Pioneira. 1979. Sociologia empírica do lazer. São Paulo: Perspectiva.

1980. Valores e conteúdos culturais do lazer. Tradução de Regina Maria Vieria. São Paulo: SESC.

DRUMAZEDIER, Joffre. 1973. Lazer e cultura popular. Tradução de Maria de Lourdes S. Machado. São Paulo:Perspectiva.

DURÃES, Wladimir de Oliveira. 1998. O lazer nas relações de trabalho. In: CONGRESSO MUNIDAL DO LAZER, 5., São Paulo: SESC. CD-ROM.

FERNANDES, Eda C. 1996. Qualidade de vida no trabalho: como medir para melhorar. Salvador: Casa da Qualidade.

FRANÇA, Ana Cristina Limongi. 1996. Indicadores empresariais de qualidade de vida no trabalho. Tese (Doutorado). Universidade de São Paulo, São Paulo.

GATTAI, Maria Cristina Pinto. 1993. A importância do lazer na empresa. Tese (Mestrado). Universidade de São Paulo. KRIPPENDORF, Jost. 1989. Sociologia do Turismo: para uma nova compreensão do lazer e das viagens. Rio de Janeiro: Civilização Brasileira.

LOUREIRO, Luís Augusto Zafalon. 1998. Tempo livre e a teoria das inteligências múltiplas segundo Howard Gardner. In: CONGRESSO MUNDIAL DE LAZER, $5^{\circ}$, São Paulo: SESC. CD-ROM.

MANFREDI, Silvia Maria. 1998. Trabalho, qualificação e competência organizacional - das dimensões conceituais e políticas. Revista Educação e Sociedade, ano XIX, n. 64/especial, p.13-43.

MARCELINO, NeIson Carvalho. 1990. Lazer e educação. 2 ed. Campinas: Papirus. 1996. Estudos de Lazer: uma introdução. Campinas: Autores Associados.

1995. Lazer: formação e atuação profissional. Campinas: Papirus.

MARIOTTI, Humberto. 1995. Organizações de aprendizagem: educação continuada e a empresa do futuro. São Paulo: Atlas.

MEDEIROS, Ethel Bauzer. 1971. O lazer no planejamento urbano. Rio de Janeiro: Fundação Getúlio Vargas.

MORIN, Edgar. 1999. Revista É, São Paulo: SESC, ano 6, n. 4, out.

MUNNÉ, Frederic. 1980. Psicosociologia del tiempo libre: um enfoque crítico. México: Trillas.

PARKER, Stanley, 1978. Sociologia do lazer. Tradução de Heloisa Toller Gomes. Rio de Janeiro: Zahar.

RAMALHO, Claudia Martins. 1999. Ginástica Laboral, caminho para uma vida mais saudável no trabalho. Revista CIPA, ano XX, n. 232.

SCHERMERHORN JR., John R. 1999. Administração. Rio de Janeiro: Livros Técnicos e Científicos.

SERVIÇO SOCIAL DA INDÚSTRIA. s.d. Produtos e Serviços: para investir em qualidade de vida e competitividade. Brasília: SESI.

TIRONI, Luis Fernando. 1993. Indicadores de qualidade e produtividade: conceitos e usos. Revista Indicadores da Qualidade e Produtividade, Brasília, v.1 n.1, fev. 